\title{
Parental Knowledge and Attitudes to Childhood Hearing Loss and Hearing Services in the Solomon Islands
}

\author{
Annette Kaspar ${ }^{\mathrm{a}, \mathrm{b}, *}$, Obiga Newton $^{\mathrm{b}}$, Joseph Kei ${ }^{\mathrm{a}}$, Carlie Driscoll ${ }^{\mathrm{a}}$, De Wet Swanepoel ${ }^{\mathrm{c}}$, \\ Helen Goulios ${ }^{d}$ \\ ${ }^{a}$ Hearing Research Unit for Children, School of Health and Rehabilitation Sciences, University of Queensland, \\ Australia \\ ${ }^{\mathrm{b}}$ ENT Clinic, National Referral Hospital, Honiara, Solomon Islands \\ ${ }^{\mathrm{c}}$ Department of Speech-Language Pathology and Audiology, University of Pretoria, South Africa \\ ${ }^{d}$ School of Anatomy, Physiology and Human Biology, University of Western Australia, Australia \\ *Corresponding author. School of Health and Rehabilitation Sciences, University of Queensland, Brisbane, 4072, \\ Australia. E-mail address: annette.kaspar@gmail.com (A. Kaspar).
}

\section{Abstract}

Objective: An understanding of parental knowledge and attitudes towards childhood hearing loss is essential to the successful implementation of audiology services. The present study aimed to investigate parental knowledge and attitudes among parents in the Solomon Islands.

Methods and materials: A total of 100 mothers and 50 fathers were administered a questionnaire via semi-structured interviews.

Results: Highest parental awareness of aetiology of childhood hearing loss was noted for otitis media (94\%), noise exposure (87.3\%), and family history (72.7\%). The highest parental awareness concerning public health initiatives to reduce/prevent otitis media was noted for routine childhood immunizations (84\%) and breast-feeding $(76 \%)$. Higher rates of knowledge in fathers than in mothers included otitis media $(p=0.038)$, noise exposure $(p=0.007)$, and breast- 
feeding ( $p=0.031$ ). Approximately half of parents $(56 \%)$ agreed that curses may cause hearing loss. Overall parental responses showed positive support for infant hearing screening programs (96\%) and school-based ear and hearing health examinations (99.3\%).

Conclusions: High levels of parental readiness and support for childhood hearing services in the Solomon Islands was evident. Knowledge of aetiology of childhood hearing loss was highest for otitis media, noise exposure, and family history. Knowledge and attitudes of fathers to childhood hearing loss and hearing services was either the same or better than that of mothers.

\section{Keywords}

Pacific Islands; Parental knowledge; Parental attitude; Childhood hearing loss; Childhood hearing services

\section{Introduction}

The successful implementation of audiology services in developing countries depends on community support and acceptance of hearing healthcare programs [1]. An appreciation of parental knowledge and attitudes towards childhood hearing loss and hearing services is essential to the development of relevant and contextually appropriate audiology programs for children. While negative attitudes may persist in some developing countries towards people with a hearing disability [2], there is also evidence that parents are generally very supportive of early identification and intervention services for infants and children with sensorineural hearing loss [3-6]. Early hearing detection programs are usually based on a biomedical model of health care, however, the development of paediatric audiology initiatives should also consider non- 
biomedical beliefs regarding childhood hearing impairment, as these may influence parental hearing health-care and health-seeking behaviour [7-9].

Audiology services are limited or non-existent in the Pacific Islands [10]. Yet, the World Health Organisation estimates that this region has among the highest global burden of hearing loss worldwide [11]. Among children, in particular, a significant proportion of hearing loss is due to avoidable causes such as otitis media (OM) and infectious diseases that may be prevented through immunizations [12]. The Oceania region is reported to have the second highest overall prevalence of hearing impairment caused by OM worldwide (51.23 per ten thousand), as well as the second highest rate of OM-related hearing loss for children 5 years and younger ( 3.02 per thousand) [13]. It is also estimated that this region has the highest incidence of Chronic Suppurative Otitis Media (CSOM) in the first year of life (35.96 per thousand), and the world's highest mortality rate due to complications of CSOM (101.1 deaths each year per 10 million) [13].

In view of the current status of childhood hearing loss in the Pacific Islands, a public health approach is recommended for the implementation of paediatric audiology services [14]. The avoidable causes of childhood hearing loss could be addressed through existing public and primary healthcare frameworks. The integration of audiology services into World Health Organisation (WHO) and United Nations Children's Emergency Fund (UNICEF) initiatives for children could promote greater population coverage and community acceptance of new hearing health programs (i.e., WHO Global School Health Program, UNICEF Expanded Program 
on Immunization). A close collaboration with the local Ear Nose and Throat (ENT) Clinic is also desirable to address the urgent public health threat of OM and its complications [15].

A pilot project is currently underway to investigate the integration of paediatric audiology services at the ENT Clinic of the National Referral Hospital in the Solomon Islands, a developing nation of the Pacific Island region (See Figure 1. Map of the Solomon Islands; Table 1. Solomon Islands Country Profile). Most healthcare services are provided free of charge under the Solomon Islands Ministry of Health and Medical Services, and the World Health Organisation and UNICEF are actively working with the national government to improve child health and development, as well as services for children with a disability [16-18]. There is currently no published evidence on community attitudes towards childhood hearing impairment in the Pacific Islands. However, earlier studies by medical anthropologists in Papua New Guinea (PNG) suggest that biomedical health care services may co-exist and be well-accepted by communities within the local framework of non-biomedical beliefs [19-21].

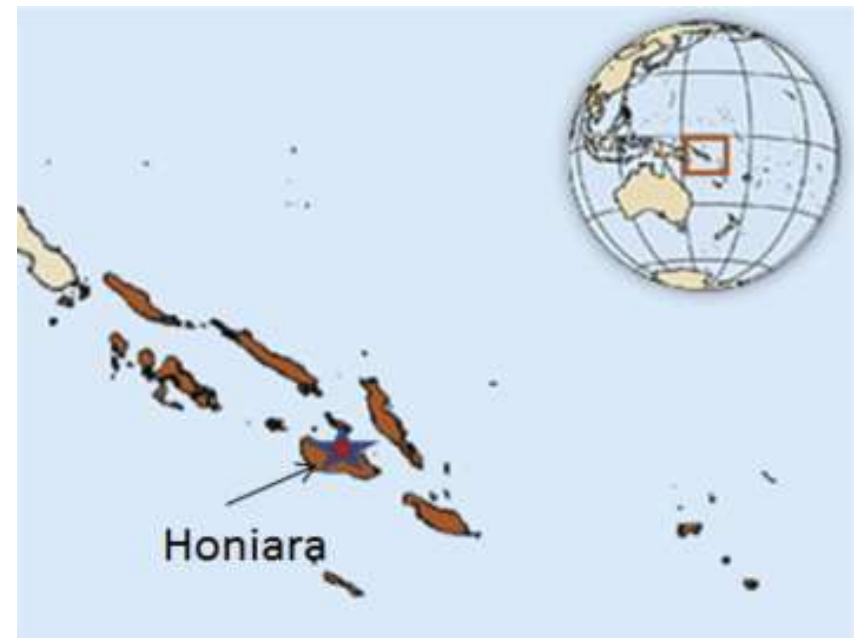

Fig. 1. Map of the Solomon Islands. 
Table 1. Solomon Islands country profile.

\section{Solomon Islands country profile}

\author{
Capital City \\ Population \\ (July 2016 estimate)
}

Age Structure

(2016 estimate)

Median Age

(2016 estimate)

Urbanization

(2015)

Mother's mean age at first birth

Total fertility rate

(2016 estimate)

Ethnic groups

(2009 estimate)

Languages

Literacy

(2009 estimate)

School Life Expectancy (primary to

tertiary education)

(2007)
Honiara

Country total: 635,027

(Honiara: 73,000 (2014))

$0-14$ years: $35.13 \%$

$15-24$ years: $20.01 \%$

$25-54$ years: $36.12 \%$

55-64 years: $4.55 \%$

65 years and older: $4.2 \%$

Total: 22.2 years

Male: 22 years

Female: 22.4 years

Urban population $=22.3 \%$ of total population

21.6 years

3.22 children born/woman

Melanesian (95.3\%), Polynesian (3.1\%), Micronesian (1.2\%), Other (0.3\%)

Solomon Pijin (lingua franca), English (official but only spoken by $1-2 \%$ of the population), 120 local languages

Definition: Age 15 years and older, and can read and write

Total population: $84.1 \%$

Male: $88.9 \%$

Female: $79.2 \%$

Total: 9 years

Male: 10 years

Female: 9 years

(Source: Adapted from CIA World Factbook www.indexmundi.com/solomon islands/demographics profile.html.) 
In order to optimize the success of the evolving audiology service in the Solomon Islands, the present study was conducted to investigate parental knowledge and attitudes towards childhood hearing loss and hearing services. This study differs from the four similar studies from developing countries by (1) addressing conductive as well as sensorineural hearing loss, (2) investigating hearing services for school-age children as well as infants, and (3) including fathers as well as mothers in the study sample [3-6]. The inclusion of fathers in the present study acknowledges the significant and active role of men in the healthcare of their children in many Pacific Islands nations.

Study findings will be used to develop health promotion activities aimed at reducing the preventable causes of hearing loss, which should further contribute to improvements in maternal and child public health as advocated by the United Nations ratified Sustainable Development Goals [22]. Given the limited information on childhood hearing loss from the Pacific Islands, this study will also serve other ear and hearing health programmes in the Pacific region.

\section{Method}

\section{Ethical approval}

Ethical approval for the study was obtained from the National Health Research \& Ethics Committee of the Solomon Islands Ministry of Health and Medical Services, and the University of Queensland Medical Research Ethics Committee. Gatekeeper approval for the study was also obtained from the Honiara City Council (Public Health Services), Solomon Islands. 


\section{Participants}

A face-to-face interview was conducted with 153 parents (102 mothers, 51 fathers) attending Child Welfare Clinics (CWCs) and community Outpatient Departments (OPDs) in the capital city Honiara, conveniently sampled during November 2016 to February 2017. This population was chosen as the children of these parents will be the primary recipients of the emerging community-based childhood ear and hearing programs. The WHO reports the national immunization coverage rate for first dose Diphtheria-Tetanus-Pertussis (DTP) to be $93.99 \%$ (administered at CWCs at 6 weeks of age), suggesting that our study participants are a representative sample of parents in Honiara [23].

Three largest community clinics were approached for participation in this study (Mataniko, Kukum, and Naha). All participants were required to be 18 years or older to avoid difficulty in obtaining informed consent for minors; the national average of mother's age at first birth is 21.6 years (See Table 1. Solomon Islands Country Profile), and we noted that all women attending the clinics on the days of data collection were over 18 years of age. Parental education level data were not collected out of concerns of cultural sensitivity, however, national school life expectancy is similar for both males and females (See Table 1. Solomon Islands Country Profile). All participation was voluntary.

A total of 153 participants were interviewed, however, 3 interviews were excluded to ensure internal consistency of data collection ( 2 interviews were conducted in the Ranonga language, 1 participant completed the questionnaire herself). 
A total of 150 parents were, therefore, included for data analysis. There were 100 mothers and 50 fathers, and no parents belonged to the same child. Mean and median age of participants could not be determined as some participants did not know their exact age. As it is common practice in the Solomon Islands for participants to report their age according to decade (i.e., "30+" means 30-39 years of age), participant age for data analysis was classified according to decade (See Table 2. Study Participant Age and Gender Information). The majority of participants were in the $20-29$ and $30-39$ age categories.

Table 2. Study participant age and gender information.

$\begin{array}{lccccccc}\text { Age }(\text { years }) & <\mathbf{2 0} \text { yr (n) } & \mathbf{2 0 - 2 9} \text { yr (n) } & \mathbf{3 0 - 3 9} \text { yr (n) } & \mathbf{4 0 - 4 9} \text { yr (n) } & \mathbf{5 0 - 5 9} \text { yr (n) } & \mathbf{6 0 - 6 9} \text { yr (n) } & \text { Total (n) } \\ \text { Mothers } & 12 & 48 & 34 & 6 & - & - & 100 \\ \text { Fathers } & 0 & 11 & 29 & 7 & 1 & 2 & 50 \\ \text { Total (n) } & 12 & 59 & 63 & 13 & 1 & 2 & 150\end{array}$

All mothers in the study were drawn from mothers attending community CWCs with their infants: Naha CWC ( $n=38)$, Mataniko CWC $(n=37)$, and Kukum CWC $(n=25)$. Most fathers in the study were drawn from fathers attending community OPD clinics with their children: Kukum OPD ( $n=37)$, Mataniko OPD ( $n=9)$, and Naha OPD $(n=2)$. Only 2 fathers were interviewed at CWCs: Naha CWC (n=1) and Kukum CWC (n=1).

\section{Questionnaire}

The study questionnaire was administered by one of the registered nurses of the ENT Clinic who is also a qualified Audiometrist. It was administered in a semi-structured interview style in 
the Solomon Island Pijin language. For each participant, demographic information (age, sex), and study location [Mataniko/ Kukum/Naha, CWC/OPD] were recorded prior to the administration of the questionnaire.

The questionnaire used in the present study consisted of 26 items: 9 items to ascertain knowledge on biomedical causes of childhood sensorineural hearing loss, 2 items on nonbiomedical beliefs regarding childhood hearing loss, 5 items on knowledge of OM-related conductive hearing loss and its risk factors, 4 items on hearing loss identification and intervention, and 6 items on attitudes to childhood hearing services. Parents were required to answer "yes", "no" or "unsure".

The questionnaire was an adapted version of the questionnaire used by Swanepoel and Almec [6], which itself had been modified from the original questionnaire used by Olusanya, Luxon and Wirz [3]. The present study modified two questions on non-biomedical beliefs of childhood hearing loss to reflect the reported cultural beliefs towards aetiology of disabilities in Melanesian societies (i.e., "Evil spirits can cause HL", "Curses can cause HL") [19]. Additional questions on biomedical causes of hearing impairment (i.e., family history, noise exposure) and service options (i.e., Oto-Acoustic Emission (OAE) hearing assessment, surgical intervention) were adapted from the study by Rajagopalan and colleagues [4]. Consanguinity as a risk factor for congenital hearing loss was excluded from the study as this is not practised in the Pacific Islands, and it was felt that the question would appear culturally insensitive. The items on OMrelated conductive hearing loss and associated risk-factors were adapted from the surveys by Adeyemo [24] and Srikanth and colleagues [25]. 
The recent introduction of the Measles \& Rubella Initiative in the Solomon Islands prompted the question on maternal rubella as a cause of hearing loss [26]. The annual Royal Australian College of Surgeons (RACS) ENT Surgical Visit to the Solomon Islands led to the question on attitudes to ear surgery [27]. The current development of a school-based ear and hearing program prompted the question on parental willingness for school-based services [14].

\section{Data analysis}

The study results were entered into an Excel spreadsheet by the first author (AK). Parental responses were assigned a numerical code: $\mathrm{Yes}=1, \mathrm{No}=2$, and Unsure=3. Results were then transferred into the SPSS statistical software package, and data analysis was performed in collaboration with the Audiology Division of the University of Queensland, which included consultation with a statistician. Parental responses were tallied for each question according to gender and age group. Chi-squared Linear-by-Linear Association tests were performed to detect any significant associations between response proportions (Yes/No/Unsure) and gender, and age groups, respectively (See Table 3. Summary of Parental Knowledge and Attitudes to Childhood Hearing Loss and Hearing Services in the Solomon Islands).

A "Procedures and Protocol Manual" is attached to this journal article as Supplementary Material. It is available online to encourage and facilitate similar surveys in other developing nations. 
Table 3. Summary of parental knowledge and Attitudes to childhood hearing loss and hearing services in the Solomon Islands.

\begin{tabular}{|c|c|c|c|c|c|c|c|c|c|}
\hline \multirow[t]{2}{*}{ Questions } & \multicolumn{3}{|c|}{ YES (n) } & \multicolumn{3}{|c|}{ NO(n) } & \multicolumn{3}{|c|}{ UNSURE (n) } \\
\hline & Mo & Father & $\begin{array}{l}\text { Total } \\
\mathrm{n}(\%)\end{array}$ & Mo & Father & $\begin{array}{l}\text { Total } \\
\mathrm{n}(\%)\end{array}$ & Mother & Father & $\begin{array}{l}\text { Total } \\
\mathrm{n}(\%)\end{array}$ \\
\hline \multicolumn{10}{|c|}{ Knowledge: SNHL Risk-factors } \\
\hline Babies can be born with HL & 19 & 23 & $42(28)$ & 58 & 17 & $75(50)$ & 23 & 10 & $33(22)$ \\
\hline High fever can cause HL & 33 & 26 & $\begin{array}{l}59 \\
(39.3)\end{array}$ & 34 & 10 & $\begin{array}{l}44 \\
(29.3)\end{array}$ & 33 & 14 & $\begin{array}{l}47 \\
(31.3)\end{array}$ \\
\hline Measles can cause HL & 23 & 23 & $\begin{array}{l}46 \\
(30.7)\end{array}$ & 39 & 15 & $54(36)$ & 38 & 12 & $\begin{array}{l}50 \\
(33.3)\end{array}$ \\
\hline Maternal rubella can cause HL & 24 & 26 & $\begin{array}{l}50 \\
(33.3)\end{array}$ & 29 & 7 & $36(24)$ & 47 & 17 & $\begin{array}{l}64 \\
(42.7)\end{array}$ \\
\hline Drugs/medications can cause HL & 39 & 26 & $\begin{array}{l}65 \\
(43.3)\end{array}$ & 42 & 17 & $\begin{array}{l}59 \\
(39.3)\end{array}$ & 19 & 7 & $\begin{array}{l}26 \\
(17.3)\end{array}$ \\
\hline Jaundice can cause HL & 15 & 8 & $\begin{array}{l}23 \\
(15.3)\end{array}$ & 42 & 25 & $\begin{array}{l}67 \\
(44.7)\end{array}$ & 43 & 17 & $60(40)$ \\
\hline $\begin{array}{l}\text { Delayed crying at birth can } \\
\text { cause HL }\end{array}$ & 15 & 5 & $\begin{array}{l}20 \\
(13.3)\end{array}$ & 54 & 31 & $\begin{array}{l}85 \\
(56.7)\end{array}$ & 31 & 14 & $45(30)$ \\
\hline Family history can cause HL & 68 & 41 & $\begin{array}{l}109 \\
(72.7)\end{array}$ & 22 & 6 & $\begin{array}{l}28 \\
(18.7)\end{array}$ & 10 & 3 & $\begin{array}{l}13 \\
(8.7)\end{array}$ \\
\hline Noise exposure can cause $\mathrm{HL}$ & 82 & 49 & $\begin{array}{l}131 \\
(87.3)\end{array}$ & 14 & 1 & $15(10)$ & 4 & 0 & $4(2.7)$ \\
\hline \multicolumn{10}{|c|}{ Non-Biomedical Model Beliefs } \\
\hline Evil spirits can cause HL & 17 & 16 & $33(22)$ & 58 & 29 & $87(58)$ & 25 & 5 & $30(20)$ \\
\hline Curses can cause HL & 57 & 27 & $84(56)$ & 24 & 21 & $45(30)$ & 19 & 2 & $21(14)$ \\
\hline \multicolumn{10}{|c|}{ Knowledge: OM and CHL Risk-Factors } \\
\hline $\begin{array}{l}\text { Ear discharge and OM can cause } \\
\mathrm{HL}\end{array}$ & 91 & 50 & $\begin{array}{l}141 \\
(94)\end{array}$ & 4 & 0 & $4(2.7)$ & 5 & 0 & $5(3.3)$ \\
\hline Recurrent flu can cause OM & 47 & 23 & $\begin{array}{l}70 \\
(46.7)\end{array}$ & 36 & 12 & $48(32)$ & 17 & 15 & $\begin{array}{l}32 \\
(21.3)\end{array}$ \\
\hline $\begin{array}{l}\text { Breast-feeding for first 6months } \\
\text { reduce/prevent OM }\end{array}$ & 71 & 43 & $\begin{array}{l}114 \\
(76)\end{array}$ & 20 & 6 & $\begin{array}{l}26 \\
(17.3)\end{array}$ & 9 & 1 & $\begin{array}{l}10 \\
(6.7)\end{array}$ \\
\hline $\begin{array}{l}\text { Smoke (tobacco/woodfire) can } \\
\text { predispose to OM }\end{array}$ & 45 & 24 & $69(46)$ & 29 & 13 & $42(28)$ & 26 & 13 & $39(26)$ \\
\hline $\begin{array}{l}\text { Routine childhood } \\
\text { immunizations can reduce OM }\end{array}$ & 83 & 43 & $\begin{array}{l}126 \\
(84)\end{array}$ & 9 & 4 & $\begin{array}{l}13 \\
(8.7)\end{array}$ & 8 & 3 & $\begin{array}{l}11 \\
(7.3)\end{array}$ \\
\hline \multicolumn{10}{|c|}{ Knowledge: Identification and Intervention } \\
\hline $\begin{array}{l}\text { HL can be identified soon after } \\
\text { birth }\end{array}$ & 18 & 14 & $\begin{array}{l}32 \\
(21.3)\end{array}$ & 73 & 32 & $\begin{array}{l}105 \\
(70)\end{array}$ & 9 & 4 & $\begin{array}{l}13 \\
(8.7)\end{array}$ \\
\hline Speech/language problems can & 40 & 29 & $69(46)$ & 44 & 19 & $63(42)$ & 16 & 2 & $18(12)$ \\
\hline
\end{tabular}




\begin{tabular}{cccc} 
YES $(n)$ & \multicolumn{2}{c}{ NO(n) } & \multicolumn{2}{c}{ UNSURE (n) } \\
Mother Father & $\begin{array}{l}\text { Total } \\
n(\%)\end{array}$
\end{tabular} Mother Father $\begin{gathered}\text { Total } \\
n(\%)\end{gathered} \quad$ Mother Father $\begin{gathered}\text { Total } \\
n(\%)\end{gathered}$

be a sign of $\mathrm{HL}$

\begin{tabular}{|c|c|c|c|c|c|c|c|c|c|}
\hline Treatment for $\mathrm{HL}$ is available & 58 & 25 & $\begin{array}{l}83 \\
(55.3)\end{array}$ & 10 & 7 & $\begin{array}{l}17 \\
(11.3)\end{array}$ & 32 & 18 & $\begin{array}{l}50 \\
(33.3)\end{array}$ \\
\hline $\begin{array}{l}\text { Children with } \mathrm{HL} \text { can attend } \\
\text { school }\end{array}$ & 61 & 45 & $\begin{array}{l}106 \\
(70.7)\end{array}$ & 37 & 4 & $\begin{array}{l}41 \\
(27.3)\end{array}$ & 2 & 1 & $3(2.0)$ \\
\hline \multicolumn{10}{|c|}{ Attitudes to childhood audiology services } \\
\hline $\begin{array}{l}\text { I would like my baby tested } \\
\text { soon after birth }\end{array}$ & 96 & 48 & $\begin{array}{l}144 \\
(96)\end{array}$ & 2 & 0 & $2(1.3)$ & 2 & 2 & $4(2.7)$ \\
\hline $\begin{array}{l}\text { I would accept OAE hearing } \\
\text { screening test for my baby }\end{array}$ & 91 & 49 & $\begin{array}{l}140 \\
(93.3)\end{array}$ & 6 & 0 & $6(4)$ & 3 & 1 & $4(2.7)$ \\
\hline $\begin{array}{l}\text { I would like my child tested at } \\
\text { school }\end{array}$ & 99 & 50 & $\begin{array}{l}149 \\
(99.3)\end{array}$ & 0 & 0 & $0(0)$ & 1 & 0 & $1(0.7)$ \\
\hline $\begin{array}{l}\text { I would let my child use hearing } \\
\text { aids }\end{array}$ & 93 & 48 & $\begin{array}{l}141 \\
(94)\end{array}$ & 2 & 1 & $3(2)$ & 5 & 1 & $6(4)$ \\
\hline $\begin{array}{l}\text { I would accept ear surgery for } \\
\text { my child }\end{array}$ & 62 & 34 & $96(64)$ & 23 & 7 & $30(20)$ & 15 & 9 & $24(16)$ \\
\hline I would like more information & 98 & 50 & $\begin{array}{l}148 \\
(98.7)\end{array}$ & 1 & 0 & $1(0.7)$ & 1 & 0 & $1(0.7)$ \\
\hline
\end{tabular}

SNHL=Sensorienural Hearing Loss; HL=Hearing Loss; OM=Otitis Media; CHL=Conductive Hearing Loss; $\mathrm{OAE}=$ Oto-Acoustic Emission.

\section{Results}

\section{Knowledge of aetiology of sensorineural hearing loss}

Overall, highest parental awareness for knowledge of aetiology of biomedical causes of hearing loss were obtained for noise exposure (87.3\%) and family history (72.7\%). Overall, lowest parental awareness for knowledge of aetiology of biomedical causes of hearing loss were obtained for delayed cry at birth (13.3\%) and jaundice (15.3\%). (N.B. "delayed cry at birth" refers to birth asphyxia, and we kept the same terminology that was used in the previous studies). 
There was a significant association between gender and response, with better knowledge among fathers than mothers for noise exposure $(p=0.007)$, maternal rubella $(p=0.006)$, measles $(p=0.008)$, and congenital hearing loss $(p=0.014)$ as aetiologies of childhood sensorineural hearing loss. There was also a significant association between age groups for family history $(p=0.033)$, maternal rubella $(p=0.031)$, and drugs/medications as causes of childhood hearing loss, with a general trend observed for better knowledge with increasing age. However, it should be noted that participant numbers were low in the <20yr, 50-59yr, and 60-69yr age categories.

For the two questions on non-biomedical causes of hearing loss, a total of $56 \%$ participants believed curses may cause hearing loss, and $22 \%$ participants believed evil spirits may cause hearing loss. There was a significant association between gender and response regarding evil spirits, showing that a greater number of fathers than mothers agreed with this belief $(p=0.008)$. There was also a significant association between age and response to the question on evil spirits, with a general trend observed for increasing belief in this cause with increasing age $(p=0.021)$.

\section{Knowledge of OM-related conductive hearing loss and its risk factors}

Overall knowledge for otitis media as a cause of hearing loss was excellent, with $94 \%$ of parents responding positively. Parental knowledge of public health measures to prevent/reduce otitis media was also excellent for both routine childhood immunizations (84\%) and breast-feeding (76\%). In contrast, parental knowledge of risk-factors for otitis media was poor for recurrent upper respiratory tract infections (46.7\%) and smoke exposure (46\%). 
A significant association was measured between gender and response for otitis media $(p=0.038)$ and breast-feeding $(p=0.031)$, with greater knowledge demonstrated among fathers than mothers.

\section{Knowledge of childhood hearing loss identification and intervention services}

Overall, $21.3 \%$ of parents responded that hearing loss may be identified soon after birth, $46 \%$ responded that speech/language problems may be a sign of hearing loss, $55.3 \%$ responded that treatment for hearing loss is available, and $70.7 \%$ agreed that children with hearing loss can attend school. There was a significant difference measured between mothers and fathers regarding speech/language problems as a sign of hearing loss $(p=0.011)$, with better knowledge displayed among fathers (58\%) than mothers (40\%). There was also a significant difference measured between mothers and fathers regarding attendance at school for children with hearing loss $(p=0.001)$, with $90 \%$ of fathers responding positively compared to $61 \%$ of mothers.

\section{Attitudes to pediatric audiology services}

Attitudes to childhood hearing services were very positive, with overall parental responses showing $96 \%$ acceptance of an infant hearing test, 93.3\% acceptance of an OAE screening test, 99.3\% acceptance of school-based hearing tests, $94 \%$ acceptance of hearing aids if required, $64 \%$ acceptance of surgery if required, and $98.7 \%$ interested in more information. There were no significant associations between gender or age on these questions.

\section{Discussion}


Overall, parental knowledge for otitis media, noise exposure, and family history as causes of childhood hearing loss was very high. The knowledge of otitis media as a cause of hearing loss was significantly greater in the present study (94\%) than in the previous studies from Nigeria, South Africa, and India (54-79\%) [3-6]. Knowledge of noise exposure was also better in the present study (87.3\%) than that reported in the two studies from India $(62-70.3 \%)[4,5]$. Knowledge of family history as a cause of hearing loss (72.7\%) was similar to that of the previous Indian study (67\%) [4].

The results of the present study also showed substantially better knowledge of preventive measures for otitis media than those reported from the Indian study. Results from the Indian study showed that only $12.7 \%$ of parents were aware of the benefits of immunisation, and less than $50 \%$ knew that breast-feeding could help reduce episodes of otitis media [25].

There was good knowledge for drugs/medications as a cause of childhood hearing loss. This may possibly be explained by the ototoxicity that was historically caused by quinine-based malaria treatments before the advent of the current artemisinin-based combination chemotherapy [14]. Previous studies showed variable results for this item, ranging from 9-69\% $[4,6]$. The results of the present study are similar to those of the Nigerian study (50\%) [3]. In contrast, knowledge of high fever (39.3\%), measles (30.7\%) and maternal rubella (33.3\%) as causes of childhood hearing loss were not well-known. The original study from Nigeria showed significantly higher parental awareness of measles $(73 \%)$ and high fever $(55 \%)$ as aetiological factors of hearing loss [3]. The results of the present study are comparable to reports from India and South Africa regarding maternal knowledge of high fever (26.5-50\%) and measles 
(19.6-43\%) as risk-factors for hearing loss [4-6]. No previous study investigated knowledge of maternal rubella to enable comparisons.

There was little awareness of the peri- and post-natal risk-factors for sensorineural hearing loss. Similar results were reported in a previous study from India [4], however, another study from India as well as the studies from Nigeria and South Africa, showed better scores for both jaundice (24-47\%) and delayed cry at birth (29.7-37\%) [3, 5-6]. This presents an opportunity to reinforce maternal and neonatal health care messages during hearing promotion activities. Improved maternal health care is an on-going focus of health development in the Solomon Islands, and the possible long-term impacts beyond infant survival should be part of the discussion [17-18].

For the item on knowledge regarding congenital hearing loss, the overall parental awareness was $28 \%$. This is substantially lower than previous studies where knowledge of congenital hearing loss was 63-68\% [3-4, 6]. Anecdotally, it is a common belief in the Solomon Islands that a baby is born completely healthy, and that any illness or disability occurs in the post-natal period. The fact that $50 \%$ of participants responded that babies cannot be born with hearing loss suggests these beliefs persist, and this has implications for the management of childhood hearing disability, particularly for cases of idiopathic congenital hearing loss. Anecdotally, it was also reported that blame tends to be attributed to the mother for any childhood disability, similar to previous studies from Africa [8-9]. In the present study, this question was phrased to ensure "congenital hearing loss" referred to a hearing loss already present at the time of birth, rather than an early-onset hearing loss that may be attributed to other causes. 
The knowledge of fathers was significantly better than that of mothers for the questions on noise exposure, maternal rubella, measles, congenital hearing loss, otitis media, and breastfeeding. The Solomon Islander interviewer (ON) felt that this was likely due to the higher education levels of fathers in the study, however this could not be verified as school attainment data was not collected. It is also possible that better knowledge was generally displayed among fathers because their children were older (CWC is usually reserved for 0-2 year age group, OPD for children over 2 years of age), and they were probably more experienced with childhood healthcare concerns. The interviewer also felt that good knowledge could be partly attributed to active health promotion, including a popular Health Talk radio program, and regular community-level health events.

Non-biomedical beliefs regarding causes of childhood hearing loss were reported. Approximately half of participants believed that curses may cause hearing loss, and almost a quarter believed evil spirits may cause hearing loss. More fathers than mothers believed evils spirits to be a cause of hearing loss, and it was noted by the interviewer (ON) that the majority of fathers in the study were from a province in the Solomon Islands where belief in evil spirits is particularly strong, which may have contributed to this finding. Once again, there are management implications for congenital hearing loss, particularly for cases where there is no clear biomedical aetiology. These findings are consistent with a study from PNG which reported that disability is often attributed to a supernatural cause [19]. Non-biomedical beliefs were also important in the South African study [6], but not so evident in the two studies from India [4-5]. 
Knowledge of identification of infant hearing loss was poor, consistent with the current lack of services in the Solomon Islands. This is a very different result from the previous studies from Africa and India where knowledge of early identification was $57-68 \%[3,5-6]$. The knowledge of speech and language problems as a sign of hearing loss was also poor, and should therefore be emphasized in health promotion activities to encourage parents to seek professional advice if this is observed. Knowledge of availability of treatment for hearing loss was good, and probably related to knowledge of medical or surgical interventions for conductive hearing loss.

There was an overwhelmingly positive attitude towards childhood hearing services, including community-based infant and school hearing health programs. This is similar to the previous studies [3-6]. It may be beneficial to provide hearing services at no cost to parents, as a study from South Africa found that payment for hearing screening caused some parents to refuse the service despite support for audiology care [28]. There was also evidence of parental readiness for rehabilitative interventions, similar to previous studies [3-4, 6]. Parental preference of amplification devices rather than surgery was measured, and the developing audiology service should not ignore children with long-term bilateral conductive hearing loss as candidates for amplification, in order to minimize any adverse effects on speech and language development.

Surgical intervention was the least preferred service, with $63.7 \%$ of parents responding that they would accept ear surgery for their child if required. Acceptance of surgery was greater in the study from India (89\%) [4]. The study from Nigeria on risk-factors for otitis media found that parents displayed a strong willingness to make behavioural modifications if this avoided surgical intervention [24]. ENT surgery services in the Solomon Islands currently consist of an 
annual visit from an ENT surgery team from Australia, and parental willingness for surgical intervention may assist with triage and efficiency of these visits.

Almost all parents responded positively to desiring more information on ear and hearing disorders. This suggests that there would be great parental support for community-based ear and hearing health promotion activities. These may be integrated with existing WHO or UNICEF initiatives, or even conducted independently to highlight the services of the ENT Clinic service (i.e., World Hearing and International Ear Care Day $3^{\text {rd }}$ March). Other initiatives include the development of an appropriate information pamphlet for parents [29], as well as information sessions for health professionals [30-31].

\section{Limitations of the present study}

The present study was conducted in the capital city Honiara, and different results could be expected in rural/remote regions of the Solomon Islands. The urban population generally has greater access to education and medical services than rural/remote populations. Nonbiomedical beliefs regarding healthcare are also known to be more prevalent outside urban settings. The present study did not enquire about traditional medicines. This may be important in subsequent studies given the evidence that parents' confidence in biomedical science-based medicine is reduced by antibiotic resistance, and may lead to people returning to traditional medicines [32].

Although a minimum of two staff members was planned for data collection to minimise intratester bias, only one ENT registered nurse was available to perform the interviews for the present study (N.B. The data in the studies from Nigeria and South Africa were also collected by 
only one interviewer). Although the questionnaire was validated by the original study from Nigeria [3], another validation study would have been beneficial in this case as the questionnaire was administered in another country and language. The recommendation of performing a test-retest reliability of responses has been added to the supplementary material Procedures and Protocols Manual.

There may have been some limitations associated with the Solomon Island context and Pijin language. The question on 'high fever' intended to investigate knowledge of meningitis as a cause of hearing loss. Given that malaria and dengue are also endemic infections associated with high fever in the Solomon Islands [23], it is unclear how parents interpreted 'high fever'.

Another limitation is the fact that the education level of participants was not ascertained. Future studies of this kind should document participant education to clarify whether any significant gender differences are an educational effect, or indeed a true gender effect.

\section{Conclusion}

There were high levels of reported parental support and readiness of childhood hearing services in the Solomon Islands. There were high levels of knowledge on otitis media as a major cause of childhood hearing loss, and preventive measures of routine childhood immunisations and breast-feeding were generally well-known. Curses as reported causal factors of hearing loss were also prominent in the study population. 


\section{REFERENCES}

1. J. DesGeorges. Family perceptions of early hearing detection, and intervention systems: Listening to and learning from families, Ment Retard Dev Disabil Res Rev, 9 (2003) 89-93.

2. D. Stephens, R. Stephens, A. von Eisenhart-Rothe. Attitudes towards hearing-impaired children in less developed countries: A pilot study. Audiology, 39(2000) 184-191.

3. B.O. Olusanya, L.M. Luxon, S.L. Wirz. Maternal views on infant hearing loss in a developing country. Int. J. Pediatr. Otorhinolaryng, 70 (2006) 619-623. doi: 10.1016/j.ijporl.2005.08.004

4. R. Rajagopalan, H.G. Selvarajan, A. Rajendran, B. Ninan. Grandmothers' perspective on hearing loss in children and newborn hearing screening. Indian J. Otol, 20(2015), 20-23. doi: $10.4103 / 0971-7749.129803$

5. R. Ravi, K. Yerraguntla, D.R. Gunjawate, B. Rajashekhar, L.E. Lewis, V. Guddattu. Knowledge and attitude (KA) survey regarding infant hearing loss in Karnataka, India. Int. J. Pediatr. Otorhinolaryng, 85 (2016) 1-4.

6. D.W. Swanepoel, N. Almec. Maternal views on infant hearing loss and early intervention in a South African community. Int. J. Audiol, 47 (2008) S44-S48. doi: 10.1080/14992020802252279

7. V. de Andrade, E. Ross. Beliefs and practices of Black South African traditional healers regarding hearing impairment. Int. J. Audiol, 44 (2005) 489-499.

8. A.O. Lasisi, A.J. Ajuwon. Beliefs and perceptions of ear, nose and throat-related conditions among residents of a traditional community in Ibadan, Nigeria. African J. Med. Med. Sci, 31(2002) 45-48.

9. A.I. Odebiyi, F. Togonu-Bickersteth. Concepts and management of deafness in the Yoruba medical system: a case study of traditional healers in Ile-Ife, Nigeria. Soc. Sci. Med, 24(1987) 645-649.

10. M. Sanders, N. Houghton, O. Dewes, J. McCool, P.R. Thorne. Estimated prevalence of hearing loss and provision of hearing services in Pacific Island nations. J. Prim. HIth. Care, 7(2015) 5-15.

11. World Health Organization.Estimates. (2012) Retrieved 2 August 2013, from http://www.who.int/pbd/deafness/estimates/en/index.html

12. World Health Organization. Deafness and hearing loss (2013) Retrieved 2 August 2013, from http://www.who.int/mediacentre/factsheets/fs300/en/index.html

13. L. Monasta, L.Ronfani, F. Marchetti, M. Montico, L.V. Brumatti, A. Bavcar, et al. Burden of disease caused by otitis media: systematic review and global estimates. PLOS ONE, 7(2012), e36226. doi: 10.1371/journal.pone.0036226

14. A.Kaspar, J. Kei, C. Driscoll, D.W. Swanepoel, H. Goulios. Overview of a public health approach to pediatric hearing impairment in the Pacific Islands. Int. J. Pediatr. Otorhinolaryngol, 86 (2016) 43-52.

15. P.W. Alberti. Pediatric ear, nose and throat services' demands and resources: a global perspective. Int. J. Pediatr. Otorhinolaryngol, 49 (Suppl. 1) S1-S9.

16. WHO. Solomon Islands Health System Review. HIth Sys in Transition. 2015 (5). 
17. UNICEF. Looking back, moving forward. A snapshot of UNICEF's work for Pacific Island children 2014-2015 (2014).

18. WHO. Leading the way to a healthier future. The World Health Organization in the Western Pacific Region (2012).

19. J. Byford, N. Veenstra. The importance of cultural factors in the planning of rehabilitation services in a remote area of Papua New Guinea. Dis. Rehab. 26(2004) 166175. doi: 10.1080/0963828032000159167

20. R. Feinberg. Spiritual and natural etiologies on a Polynesian outlier in Papua New Guinea. Soc. Sci. Med, 30(1990) 311-323.

21. M. Lepowsky. Sorcery and penicillin: treating illness on a Papua New Guinea island. Soc. Sci. Med, 30(1990) 1049-1063.

22. United Nations. Sustainable Development Goals Retrieved 22/01/2016, from http://www.un.org/sustainabledevelopment/sustainable-development-goals/

23. WHO Western Pacific Region, Health Information \& Intelligence Platform, Retrieved 25/09/2017, from http://hiip.wpro.who.int/portal/countryprofiles/Solomonlslands/HealthProfiles/Tabld/2 00/ArtMID/1048/ArticleD/III/Default.

24. A.A. Adeyemo. Knowledge of caregivers on the risk factors of otitis media. Indian J.Otol, 18(2012) 184-188.

25. S. Srikanth, R. Isaac, G. Rebekah, V. Rupa. Knowledge, attitudes and practices with respect to risk factors for otitis media in a rural South Indian community. Int. J. Pediatr. Otorhinolaryngol, 73 (2009) 1394-1398. doi: 10.1016/j.ijporl.2009.06.024

26. Measles \& Rubella Initiative Retrieved 25/09/2017, from http://measlesrubellainitiative.org

27. Royal Australasian College of Surgeons, Retrieved 25/09/2017, from http://www.surgeons.org/for-the-public/racs-global-health/pacific-island-countries/

28. L.J. Scheepers, D.W. Swanepoel, T. le Roux. Why parents refuse newborn hearing screening and default on follow-up rescreening - A South African perspective. Int. J. Pediatr. Otorhinolaryngol, 78 (2014) 652-658.

29. K. Joubert, E. Githinji. Quality and readability of information pamphlets on hearing and paediatric hearing loss in the Gauteng Province, South Africa. Int. J. Pediatr. Otorhinolaryngol, 78 (2014) 354-358.

30. M. López-Vázquez, P. Berruecos, L.E. Lopez, J. Cacho, J. Attitude and knowledge of hearing loss among medical doctors selected to initiate a residency in Mexico. Int. J. Audiol, 48 (2009) 101-107. doi: 10.1080/14992020802355882

31. B.O. Olusanya, A.A. Roberts. Physician education on infant hearing loss in a developing country. Pediatr. Rehab, 9(2006) 373-377. doi: 10.1080/02640410500521615

32. G.N. Njoroge, R.W. Bussmann, R. W. Traditional management of ear, nose and throat (ENT) diseases in Central Kenya. J. Ethnobiol. Ethnomed, 6(2006) 1-9. doi: 10.1186/1746-4269-2-54 


\section{Supplementary material:}

\section{Procedures and protocol manual}

The present document was written as a guide to professionals in developing countries wishing to assess parental knowledge and attitudes to childhood hearing loss and hearing services.

Assessment title: Parental knowledge and attitudes to childhood hearing loss and hearing services in a developing country.

\section{Aims and objectives}

The aims of the assessment are to evaluate:

- Parental knowledge of childhood hearing impairment in [district/country], and

- Parental support for childhood hearing services in [district/country].

The results of the assessment may be used to:

- Guide the development of hearing services for children in [district/country],

- Guide the development of health education and health promotion activities for Ear and Hearing Health in [district/country],

- Provide baseline data for comparison with subsequent surveys (i.e., To assess the effectiveness of health education and health promotion activities), and

- Provide the first information of its kind from [district/country], enabling comparison with similar studies. 


\section{Stage 1: Planning and Preparation}

\section{Ethical Approval}

Ethical approval for the assessment must be obtained from the appropriate authorities (i.e., Ministry of Health and Medical Services). Gatekeeper approval may also need to be obtained (i.e., Hospital Management Committee).

\section{Time Frame}

The time frame for the assessment will vary depending on human resource allocation and availability. To complete the assessment, the staff member(s) is required to organise approval for the assessment, prepare the required documentation, conduct the interviews, perform data handling and analysis, and write a report of the assessment results.

\section{Preparation of a Written Protocol}

The present document was written to assist the staff member(s) wishing to perform this assessment to ensure all aspects are considered and clarified. It was developed by an Australian International Health Development Audiologist (Annette Kaspar) in collaboration with the Audiology Division of the University of Queensland (Brisbane, Australia).

\section{Personnel}

The assessment may be performed by one staff member, however, a minimum of two staff members is recommended. One staff member should be designated as the team leader. 


\section{Study Population}

The study population should consist of the primary recipients of the intended ear and hearing service for children. An appropriate setting should be identified, and it should consist of a representative sample of parents/caregivers from the community (i.e., parents attending Child Welfare Clinics).

\section{Study Design}

The study may use a convenience sampling design. This method was used in previous studies of this kind, and is a cost-effective method appropriate for this population (Olusanya, Luxon, \& Wirz, 2006; Swanepoel \& Almec, 2008).

\section{Sampling Method and Sample Size}

The study population will be drawn from the chosen setting (i.e., Child Welfare Clinics). It is helpful to justify your choice of setting (i.e., "Mataniko Child Welfare Clinic was chosen as it is the largest clinic", "These two clinics were chosen to enable comparison between parents living in urban and rural areas).

The chosen setting should be invited to participate in the assessment, and data collection may be scheduled once gatekeeper approval has been obtained. It is helpful to short-list a number of possible settings for the assessment, just in case your preferred setting(s) is unable to participate. 
On the day of data collection, an announcement about the assessment should be made, including an invitation to attending parents to participate. This announcement should be made regularly throughout the day as new parents attend the clinic.

A minimum sample size of 100 participants is recommended for the study. A 1:1 mother/father ratio is desirable. Participating mothers and fathers may be parents of the same child, however, the questionnaire should be administered to each parent independently and separately.

\section{Development of assessment questionnaire}

A review of the literature is recommended to develop a questionnaire that is suitable to the assessment aims. The original questionnaire was developed to ascertain maternal knowledge and attitudes towards infant sensorineural hearing loss and interventions (Olusanya, et al., 2006). Based on their literature review, the authors of the study from the Solomon Islands expanded the original questionnaire to include items on cultural beliefs regarding childhood hearing loss, parental knowledge of risk-factors for otitis media, and parental attitudes towards services for childhood hearing loss (i.e., infant and school-based hearing programmes, amplification, surgical intervention). Questions should be appropriate to the cultural and social setting.

\section{Training of staff member(s)}

The assessment questionnaire will be administered verbally to the participants by the designated staff member(s). Training in the administration of the questionnaire should be 
considered if the staff member(s) does not have prior experience of performing this kind of assessment: this is to ensure methodology is robust and satisfies local cultural considerations. An assessment of competency to participate in the data collection may be considered.

\section{Equipment and Consumables}

All requirements, as listed below, may be contained within a simple plastic folder for utilization by the staff member(s). The forms should be available in the appropriate language(s) as determined by the staff member(s).

- Information Sheet for Participants - Parental Knowledge and Attitudes to Childhood Hearing Loss and Hearing Services in [district/country]

- Participant Consent Form - Parental Knowledge and Attitudes to Childhood Hearing Loss and Hearing Services in [district/country]

- Questionnaire - Parental Knowledge and Attitudes to Childhood Hearing Loss and Hearing Services in [district/country]

- Staff member business cards with contact details

- Pens

\section{Quality Control}

The following measures should be implemented to ensure maximum quality control for the assessment:

- All staff members will undergo training in the administration of the questionnaire to ensure consistency and reliability, 
- $\quad$ Regular review with the team leader during the assessment period to enable any clarification of issues if/as they arise,

- At least two staff members should be involved in the administration of the questionnaire to prevent tester bias,

- Questionnaire form requires the identification and signature of the staff member administering the questionnaire,

- $\quad$ Team leader reviews all questionnaires, and gives feedback to staff members as required (e.g., Incomplete section(s) of questionnaire), and

- Team leader to give regular feedback to staff member(s) on their performance and provide refresher training as necessary.

The validation of the questionnaire as an effective assessment tool was previously performed in the literature (Olusanya, et al., 2006; Rajagopalan, Selvarajan, Rajendran, \& Ninan, 2015; Ravi et al., 2016; Srikanth, Isaac, Rebekah, \& Rupa, 2009; Swanepoel \& Almec, 2008). A validation study is recommended if the questionnaire is performed in another language and/or country.

\section{Logistics and Administration}

The team leader is responsible for the overall logistics and administration of the assessment.

The team leader will be responsible for:

- Obtaining ethical approval for the assessment from the relevant authorities,

- Training staff member(s) in the administration of the assessment questionnaire,

- Developing the information sheets and consent forms, and 
- Developing a protocol for the assessment that is relevant to their context (may be based on the present document).

The team leader may work in collaboration with the staff member(s) to:

- $\quad$ Obtain support from relevant authorities for the assessment,

- $\quad$ Ensure the information and consent forms are appropriate for the study population (i.e., Language), and

- $\quad$ Ensure the training of the staff member(s) is complete and appropriate.

\section{Budget and Funding}

The available budget will determine the time frame and human resources for the assessment. The main costs to consider are staff salaries, consumables, and any travel and/or accommodation requirements.

Funding for the assessment may be difficult to obtain, however, options include the Health Ministry of the national government, national university/research institutions, and nongovernment organizations such as "Hear the World" or the WHO World Wide Hearing Project. 


\section{Stage 2: Conducting the Study}

The recommended work flow on the day of data collection is summarised in Figure 1.

Figure 1. Parental Knowledge and Attitudes to Childhood Hearing Loss and Hearing Services Study Work Flow Chart
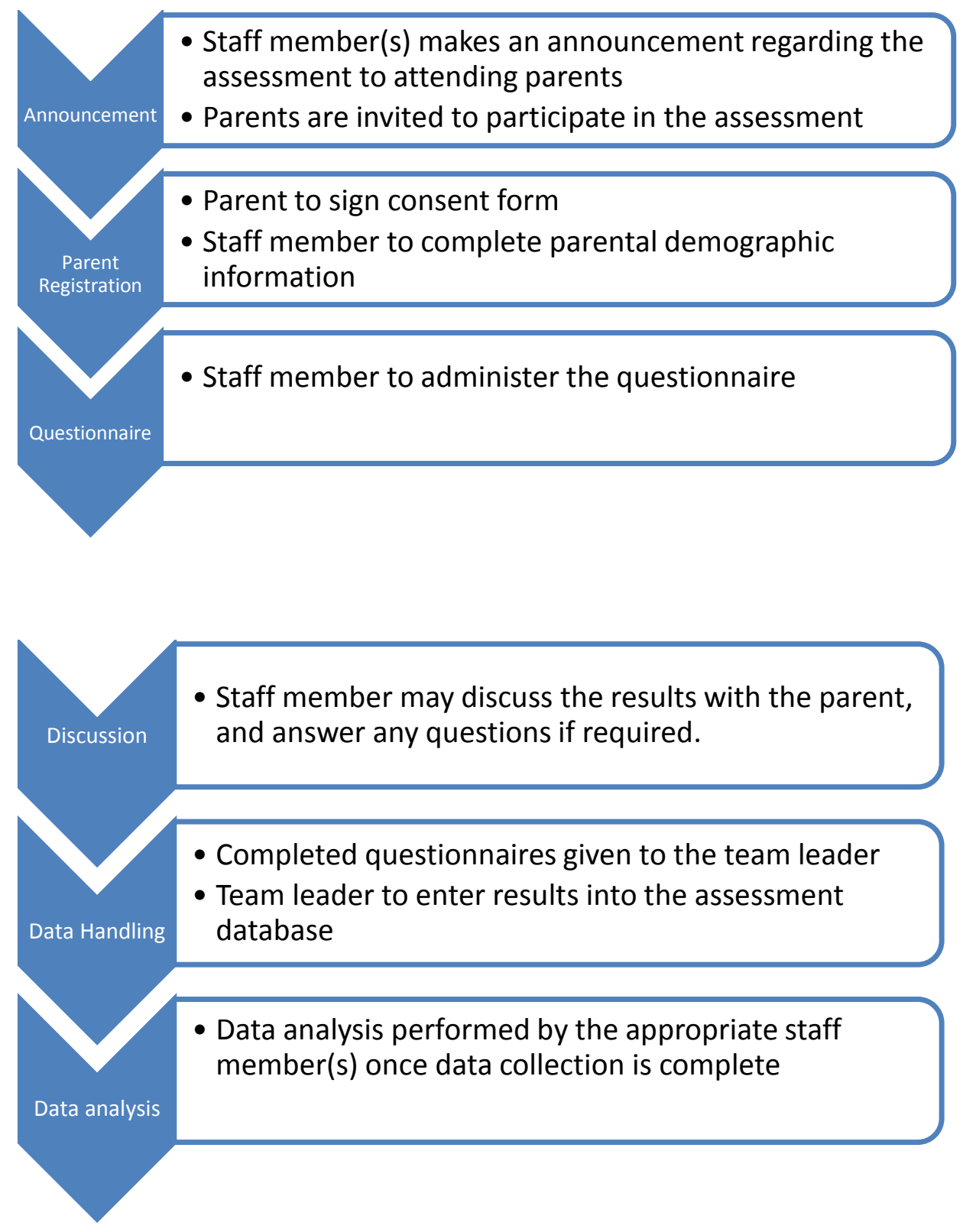


\section{Recruitment of Participants}

On the day of data collection, an announcement will be made by a staff member of the team to parents attending the chosen setting. The announcement will be made at the start of the day, and then at regular intervals throughout the day if new parents arrive. The announcement will introduce the members of the assessment team, and then describe the aims of the project and the participant requirements. Attending parents will then be invited to participate in the study.

Parents willing to participate in the study will be shown to a private area that has been allocated for the project. They will be given more detailed information on the study (i.e., Information Sheet), and asked to sign the consent form if they are still willing to participate.

\section{Administration of Questionnaire}

\section{a. Demographic information}

The staff member performing the interview will complete the demographic information on the questionnaire form as follows:

- $\quad$ Date of Assessment

- Location of Assessment

- $\quad$ Clinician name and signature

- $\quad$ Participant Name (First and Last Name)

- $\quad$ Participant Age (in years)

- $\quad$ Circle Male/Female as appropriate 
Depending on the scope of the assessment, the questionnaire may also include demographic information pertaining to: number of children, socio-economic status, parental education history, etc.

\section{b. Questionnaire}

The questionnaire will be administered in a semi-structured interview style. The staff member will ask the questions in the order in which they appear on the questionnaire (i.e., Begin with Question 1, end with Question 26). The staff member may clarify the questions as required in the event of language or cultural barriers (e.g., "yellow skin" instead of "jaundice").

The staff member will begin by explaining to the participant that they will be asked a series of questions relating to ear and hearing problems in infants and children. The participants will then be instructed to answer these questions with "yes", "no", or "not sure". The staff member will record the participant's response to each question on the questionnaire form.

\section{Data Handling and Analysis}

All data handling and analysis will be done by the team leader.

- All completed questionnaires will be given to the team leader by the other staff member(s),

- The team leader will review all questionnaires to ensure all items are completed. Where information is missing, the team leader will consult the relevant staff member and, if appropriate, contact the participant, 
- The team leader will assign a code-identifier to each participant. This will be entered on the "Office Use Only" section of the Consent and Questionnaire forms, and

- $\quad$ The team leader will enter all data into "Data Entry Spreadsheet Parental Knowledge and Attitudes to Childhood Hearing Loss and Hearing Services in [district/country]"

An example of coding strategy for data entry is described in Table 1: Coding Strategy for "Parental Knowledge and Attitudes to Childhood Hearing Loss and Hearing Services in the Solomon Islands" Assessment.

Table 1: Coding Strategy for "Parental Knowledge and Attitudes to Childhood Hearing Loss and Hearing Services in the Solomon Islands" Assessment.

\begin{tabular}{|l|l|l|}
\hline Item & Description & Code \\
\hline Participant ID & Numeric Code in order of participation & 1 , etc. \\
\hline Location & Mataniko Child Welfare Clinic (CWC) & 1 \\
\cline { 2 - 3 } & Naha CWC & 2 \\
\cline { 2 - 3 } & Kukum CWC & 3 \\
\cline { 2 - 3 } & Mataniko Outpatient Department (OPD) & 4 \\
\cline { 2 - 3 } & Kukum OPD & 5 \\
\hline Male/Female & Male & 1 \\
\cline { 2 - 3 } & Female & 2 \\
\hline Parent & Yes & 2 \\
\cline { 2 - 3 } & No & \\
\hline
\end{tabular}




\begin{tabular}{|l|l|l|}
\hline \multirow{3}{*}{ Yes/No/Unsure } & Yes & 1 \\
\cline { 2 - 3 } & No & 2 \\
\cline { 2 - 3 } & Unsure & 3 \\
\hline Interviewer ID & Obiga Newton & 1 \\
\cline { 2 - 3 } & Annette Kaspar & 2 \\
\hline
\end{tabular}

The team leader will descriptively analyse the data to provide the following information:

\section{a. Demographic information}

A descriptive analysis will be performed for the total number of participants, and number/proportion of mothers/fathers. The analysis will include age range (mean and standard deviation) for the total number of participants, as well as for each subgroup. If exact age of participants cannot be determined, the age of participants may be described in decade subgroups (i.e., 20-29 years, 30-39 years). Results will be presented in tabulated form using a cross-analysis (i.e., age subgroup $\mathrm{x}$ mother/father). An example of demographic information analysis is provided in Table 2. 
Table 2. Demographic information for "“Parental Knowledge and Attitudes to Childhood Hearing Loss and Hearing Services in the Solomon Islands" Assessment.

\begin{tabular}{|l|l|l|l|l|l|l|l|}
\hline Age & $<20 y r$ & $20-29 y r$ & $30-39 y r$ & $40-49 y r$ & $50-59 y r$ & $60-69 y r$ & Total \\
\hline Mothers & 12 & 49 & 33 & 6 & - & - & 100 \\
\hline Fathers & 0 & 10 & 26 & 7 & 1 & 2 & 50 \\
\hline Total & 12 & 59 & 59 & 13 & 1 & 2 & 150 \\
\hline
\end{tabular}

\section{b. Analysis of variables}

For each item of the questionnaire, the number of participants answering "Yes", "No", or "Unsure" will be tallied. The data will be analysed using Chi-Squared to investigate if there is a significant difference in response proportions:

- Between mothers/ fathers,

- Between age groups overall, and

- Between mothers/fathers and age groups.

Depending on the other demographic information collected, data may be analysed for significant difference in response proportions for other variables such as:

- Geographic location (urban vs rural setting),

- Socio-economic status (SES) (high vs low SES), or

- Parental education (completed primary school vs completed secondary school). 
The results will be presented in tabulated form, and any significant findings highlighted. An example is provided in Table 3. Parental Attitudes to Childhood Hearing Services in the Solomon Islands.

Table 3. Parental Attitudes to Childhood Hearing Services in the Solomon Islands.

\begin{tabular}{|c|l|l|l|l|l|l|}
\hline QUESTION & \multicolumn{2}{l|}{ YES (\%) } & \multicolumn{2}{l|}{ NO (\%) } & \multicolumn{2}{l|}{ UNSURE (\%) } \\
\cline { 2 - 7 } & Mother & Father & Mother & Father & Mother & Father \\
\hline $\begin{array}{l}\text { 1. I would like my baby tested soon after } \\
\text { birth }\end{array}$ & 96 & 96 & 2 & 0 & 2 & 4 \\
\hline $\begin{array}{l}\text { 2. I would accept OAE hearing screening } \\
\text { test for my baby }\end{array}$ & 91 & 98 & 6 & 0 & 3 & 2 \\
\hline 3. I would like my child tested at school & 99 & 100 & 0 & 0 & 1 & 0 \\
\hline 4. I would let my child use hearing aids & 93 & 96 & 2 & 2 & 5 & 2 \\
\hline $\begin{array}{l}\text { 5. I would accept ear surgery for my child } \\
\text { if required }\end{array}$ & 62 & 68 & 23 & 14 & 15 & 18 \\
\hline 6. I would like more information & 98 & 100 & 1 & 0 & 1 & 0 \\
\hline
\end{tabular}

\section{Stage 3: Publication of Results}

\section{Formal publication in a peer-reviewed journal article}

The results of this study may be written as a paper for submission to peer-reviewed journals. Similar studies have been previously published in the International Journal of Audiology and the International Journal of Paediatric Otorhinolaryngology.

\section{Formal report to [district/country] Ministry of Health or other relevant authority.}

A formal report of the assessment results should be presented to the [district/country] Ministry of Health, and/or other relevant authority/stakeholders who granted approval for the assessment. The report should summarise the key results of the assessment, and include an action plan for health education and health promotion activities based on the results. 


\section{Summary of results published in local media}

A brief description of the assessment and results, as appropriate, should be presented in a short media release. Collaboration with local Health Promotion Officers (i.e., World Health Organisation, Ministry of Health) is recommended to ensure information is appropriate and receives maximum population coverage. The aim of the media release is to increase community awareness of ear and hearing health care, and to promote any ear and hearing health promotion activities which have been planned.

\section{REFERENCES}

Olusanya, B. O., Luxon, L. M., \& Wirz, S. L. (2006). Maternal views on infant hearing loss in a developing country. International Journal of Pediatric Otorhinolaryngology, 70, 619-623. doi: 10.1016/j.ijporl.2005.08.004

Rajagopalan, R., Selvarajan, H. G., Rajendran, A., \& Ninan, B. (2015). Grandmothers' perspective on hearing loss in children and newborn hearing screening. Indian Journal of Otology, 20(1), 20-23. doi: 10.4103/0971-7749.129803

Ravi, R., Yerraguntla, K., Gunjawate, D. R., Rajashekhar, B., Lewis, L. E., \& Guddattu, V. (2016). Knowledge and attitude (KA) survey regarding infant hearing loss in Karnataka, India. International Journal of Pediatric Otorhinolaryngology, 85, 1-4.

Srikanth, S., Isaac, R., Rebekah, G., \& Rupa, V. (2009). Knowledge, attitudes and practices with respect to risk factors for otitis media in a rural South Indian community. International Journal of Pediatric Otorhinolaryngology, 73, 1394-1398. doi: 10.1016/j.ijporl.2009.06.024

Swanepoel, D., \& Almec, N. (2008). Maternal views on infant hearing loss and early intervention in a South African community. International Journal of Audiology, 47 (Suppl. 1), S44-S48. doi: $10.1080 / 14992020802252279$ 